University of Nebraska - Lincoln

DigitalCommons@University of Nebraska - Lincoln

\title{
Alcohol and HIV Decrease Proteasome and Immunoproteasome Function in Macrophages: Implications for Impaired Immune Function During Disease
}

\author{
James Haorah \\ Liver Study Unit, The Center for Neurovirology and Neurodegenerative Disorders, University of Nebraska \\ Medical Center, Omaha, NE 68198-5215, USA \\ David Heilman \\ Liver Study Unit, The Center for Neurovirology and Neurodegenerative Disorders, University of Nebraska \\ Medical Center, Omaha, NE 68198-5215, USA \\ Casey Diekmann \\ Liver Study Unit, The Center for Neurovirology and Neurodegenerative Disorders, University of Nebraska \\ Medical Center, Omaha, NE 68198-5215, USA \\ Natalia Osna \\ The Veterans Affairs Medical Center, Omaha, NE USA \\ Terrence M. Donohue Jr. \\ The Veterans Affairs Medical Center, Omaha, NE USA \\ Sellone this and fadditionahworkstat:https://digitalcommons.unl.edu/publichealthresources \\ Part of the Public Health Commons
}

Haorah, James; Heilman, David; Diekmann, Casey; Osna, Natalia; Donohue Jr., Terrence M.; Ghorpade, Anuja; and Persidsky, Yuri, "Alcohol and HIV Decrease Proteasome and Immunoproteasome Function in Macrophages: Implications for Impaired Immune Function During Disease" (2004). Public Health Resources. 57.

https://digitalcommons.unl.edu/publichealthresources/57

This Article is brought to you for free and open access by the Public Health Resources at DigitalCommons@University of Nebraska - Lincoln. It has been accepted for inclusion in Public Health Resources by an authorized administrator of DigitalCommons@University of Nebraska - Lincoln. 


\section{Authors}

James Haorah, David Heilman, Casey Diekmann, Natalia Osna, Terrence M. Donohue Jr., Anuja Ghorpade, and Yuri Persidsky 


\title{
Alcohol and HIV decrease proteasome and immunoproteasome function in macrophages: implications for impaired immune function during disease
}

\author{
James Haorah $^{\mathrm{a}, \mathrm{b}}$, David Heilman ${ }^{\mathrm{a}, \mathrm{b}}$, Casey Diekmann ${ }^{\mathrm{a}, \mathrm{b}}$, Natalia Osna ${ }^{\mathrm{c}}$, \\ Terrence M. Donohue Jr. ${ }^{c}$, Anuja Ghorpade ${ }^{a, b}$, Yuri Persidsky ${ }^{a, b, *}$ \\ ${ }^{a}$ Liver Study Unit, The Center for Neurovirology and Neurodegenerative Disorders, University of Nebraska Medical Center, \\ Omaha, NE 68198-5215, USA \\ ${ }^{\mathrm{b}}$ Department of Pathology and Microbiology, University of Nebraska Medical Center, Omaha, NE 68198-5215, USA \\ ${ }^{\mathrm{c}}$ The Veterans Affairs Medical Center, Omaha, NE USA
}

Received 9 March 2004; accepted 12 July 2004

\begin{abstract}
Proteasomes (proteinase complexes, PR) and immunoproteasomes (IPR) degrade damaged proteins and affect protein processing required for antigen presentation by mononuclear phagocytes. These critical immune processes are attenuated during progressive HIV-1 infection and are affected by alcohol abuse. To investigate the mechanisms underlying these functional changes, we measured PR and CYP2E1 activities [an ethanol (EtOH) metabolizing enzyme] and reactive oxygen species (ROS) in human monocyte-derived macrophages (MDM) following HIV-1 infection and EtOH treatment. We observed progressive declines of PR activity and PR/IPR contents in HIV-1-infected MDM. PR activity and IPR expression increased after IFN- $\gamma$ stimulation but reduced after HIV-1 infection. EtOH inhibited both IFN- $\gamma$-induced PR and IPR. Paradoxically, EtOH attenuated PR catalytic activity in infected MDM and suppressed viral replication. Elevated ROS followed EtOH exposure and paralleled decreased PR activity. The latter was restored by anti-oxidant. The data support the notion that HIV-1 infection and EtOH may work in concert to affect immune function including antigen presentation and thereby affect disease progression.
\end{abstract}

Keywords: Mononuclear phagocytes; CYP2E1; Reactive oxygen species; Antigen presentation

\section{Introduction}

Alcohol abuse can affect the progression of HIV-1 disease $[1,2]$. Acute and chronic alcohol abuse impairs a broad range of immune functions and thus is implicated as a cofactor in HIV-1 infection. Nonetheless, the mechanisms by which alcohol affects the HIV-1 cellular targets are unknown. Ethanol (EtOH) exposure leads to diminished $\mathrm{T}$ - and B-lymphocyte numbers, immunoglobulin and pro-inflammatory cytokine [tumor necrosis factor

\footnotetext{
${ }^{*}$ Corresponding author. Fax: +1 4025598922.

E-mail address: ypersids@unmc.edu (Y. Persidsky).
}

(TNF)- $\alpha$, interleukin (IL)-1 $\beta$, and IL-6] production [3-6]. EtOH can also affect antigen presentation by macrophages and dendritic cells [7], phagocytosis [8] and intracellular killing [9]. Macrophage activation induced by lipopolysaccharide is attenuated after EtOH administration [10]. EtOH induces secretion of anti-inflammatory factors (transforming growth factor $\beta$ and prostaglandin $\left.\mathrm{E}_{2}\right)[1,11,12]$. Acute EtOH intoxication can also suppress inflammatory responses in normal subjects through inhibition of accessory function and leukocyte migration [10,13-15]. In simian immunodeficiency virus (SIV)-infected animals EtOH suppresses TNF- $\alpha$ and leads to increased susceptibility to secondary infections [16]. 
Degradation of damaged or short-lived regulatory proteins is a function of the proteasome (PR). The PR consists of a $20 \mathrm{~S}$ catalytic core that is activated by binding of the PA28 regulator [17-19]. PR constitutive subunits $(\mathrm{X}, \mathrm{Y}, \mathrm{Z})$ possess chymotrypsin-like $(\mathrm{X})$, trypsin-like (Y), and peptidyl-glutamyl-peptide hydrolase (Z) activities [20,21]. PR activity is up-regulated by pro-inflammatory cytokines [interferon (IFN)- $\gamma$ TNF- $\alpha$ and IL-6] $[20,22]$. After IFN- $\gamma$ stimulation, constitutive PR subunits $X, Y$, and $Z$ are replaced by inducible PR subunits LMP2, LMP7, and MELC-1 [20,21]. Processing of protein antigens within inducible subunits of IPR is important in subsequent conjugation with the class I major histocompatibility complex (MHC) required for antigen presentation [21,23]. While no data are available to suggest that alcohol affects PR function in antigen presenting cells (APC), studies performed using liver cells point to $\mathrm{PR}$ impairment as a result of exposure to EtOH or its metabolites [24].

Microsomal enzymes belonging to the cytochrome P450 family catalyze a variety of hydroxylation reactions. Cytochrome P450 2E1 (CYP2E1) is a terminal oxidase in the microsomal respiratory chain and is involved in EtOH metabolism [25]. Monocyte-derived macrophages (MDM) and rat liver macrophages express CYP2E1 [26,27]. CYP2E1 plays a central role in EtOH metabolism by macrophages [28]. Inhibition of CYP2E1, attenuated EtOH-induced reduction of PR activities in vivo, in liver cells $[29,30]$. Such effects are assumed to be associated with increased production of reactive oxygen species (ROS). We now hypothesize that EtOH may affect PR function and in doing so affect antigen presentation. We demonstrate that both HIV-1 infection and EtOH diminish PR activity and IPR contents in macrophages and thus, may contribute to immune dysfunction in an infected human host.

\section{Materials and methods}

\subsection{Isolation and virus infection of human monocyte- derived macrophages}

Human monocytes were isolated from HIV-1, 2, and hepatitis B seronegative donors and purified by countercurrent centrifugal elutriation [31]. Monocytes were cultured at $30 \times 10^{6}$ cells/T75 flask in $10 \mathrm{ml}$ in Dulbecco's modified Eagle's medium (Sigma Chemical, St. Louis, MO) with $10 \%$ heat inactivated human serum, $1 \%$ glutamine, $50 \mu \mathrm{g} / \mathrm{ml}$ gentamicin (Sigma), $10 \mu \mathrm{g} / \mathrm{ml}$ ciprofloxacin (Sigma), and $1000 \mathrm{U} / \mathrm{ml}$ human macrophage colony-stimulating factor (a generous gift from Genetics Institute, Cambridge, MA). In parallel, monocytes were cultured in 96-well plates for viability assays at $10^{5}$ cells/ well in $100 \mu 1$ media for seven days, changing the medium every third day. MDM then were infected with cell-free macrophage-tropic strain HIV-1 $1_{\mathrm{ADA}}$ inoculum $\left(4 \times 10^{5} \mathrm{cpm} / 10^{6}\right.$ cells $)$ standardized for all experiments by reverse transcriptase (RT) activity [32]. RT activity was determined in triplicate in culture fluids after addition of $0.05 \%$ Nonidet P-40 (Sigma), $10 \mu \mathrm{g} / \mathrm{ml}$ poly(A), $0.25 \mu \mathrm{g} / \mathrm{ml}$ oligo(dt) (Pharmacia Fine Chemicals, Piscataway, NJ), and $5 \mathrm{mM}$ dithiothreitol thymidine 5 '-triphosphate $(2 \mathrm{Ci} / \mathrm{mmol}$; Amersham, Arlington Heights, IL) in Tris- $\mathrm{HCl}$ buffer ( $\mathrm{pH} 7.9$ ) for $24 \mathrm{~h}$ at $37^{\circ} \mathrm{C}$. Radiolabeled nucleic acids were precipitated with cold $10 \%$ trichloroacetic acid (TCA) and 95\% EtOH in an automatic cell harvester (Packard Instrument Company, Meriden, CT) on paper filters. Radioactivity was estimated by liquid scintillation spectroscopy. Level of infection was also assessed in MDM (3, 5, and 9 days after infection) by staining for HIV-1 p24 [using primary monoclonal antibodies (Abs) from Dako, Carpenteria, CA, detected by avidin-biotin immunoperoxidase, Vectastain Elite ABC kit, Vector Laboratories, Burlingame, CA]. Immunostained cells were analyzed with a Nikon Microphot-FXA microscope. RT results were normalized to viable cell numbers determined by 3-[4,5-dimethylthiazol-2-yl]-2,5-diphenyltetrazolium bromide (MTT) assay [33]. Briefly, after collecting the culture media from HIV-1 infected MDM in 96-well plate for RT, cells were incubated with MTT $(5 \mathrm{mg} / \mathrm{ml}$ solution of $10 \%$ FBS in PBS) for $45 \mathrm{~min}$ at $37^{\circ} \mathrm{C}$. Reduction of MTT to formazan was assessed at $490 \mathrm{~nm}$ using plate reader.

\subsection{Cell treatments}

After treating MDM with $25 \mathrm{mM}$ EtOH, ethanol concentration in culture fluids was determined by using EtOH assay kit (Diagnostic Chemicals Limited, P.E.I. Canada). This was done to assay possible evaporation of $\mathrm{EtOH}$ after 8,24 , and $48 \mathrm{~h}$ incubation at $37^{\circ} \mathrm{C}$. EtOH recovery was $95-98 \%$ when compared to the start concentration. MDM were stimulated with IFN- $\gamma(10 \mathrm{ng} / \mathrm{ml}, \mathrm{R} \& D$ Systems, Minneapolis, MN) in order to mimic immune activation in HIV-1 infected cells and to induce IPR.

\subsection{Protein extraction}

After $48 \mathrm{~h}$ treatment period, media was aspirated from T75 culture flasks, followed by two successive washes with ice-cold $20 \mathrm{mM}$ phosphate buffered saline. Cells were scraped into $1 \mathrm{ml}$ ice-cold extraction buffer $(50 \mathrm{mM}$ Tris- $\mathrm{HCl}, \mathrm{pH} 7.5$, containing $20 \%$ glycerol, $5 \mathrm{mM}$ ATP, $5 \mathrm{mM} \mathrm{MgCl}_{2}$, and $0.5 \mathrm{mM}$ DTT). After sonicating the cell suspension on ice, a $300 \mu$ lysate aliquot was stored from each sample without the protease inhibitor for the analysis of PR chymotrypsin-like activity and for the immunoblots of PR and IPR. Before subjecting to denaturing electrophoresis under non-reducing conditions, lysates were centrifuged at $14,000 \mathrm{rpm}$ $(15,000 \mathrm{~g})$ for $15 \mathrm{~min}$ at $4{ }^{\circ} \mathrm{C}$. Lysates then were 
centrifuged at $35,000 \mathrm{rpm}(105,000 \mathrm{~g})$ for $1 \mathrm{~h}$ at $4^{\circ} \mathrm{C}$ to sediment the microsome fraction for CYP2E1 assay.

\subsection{PR Chymotrypsin-like activity}

Chymotrypsin-like activity was assayed using 7-amino-4-methylcoumarin as the standard and $N$-succinyl-LEU-LEU-VAL-TYR-7-amino-4-methylcoumarin (LLVY assay) as the fluorogenic peptide substrate (Sigma). Chymotrypsin-like activity was assayed in 96-well plates containing $40 \mu \mathrm{M}$ LLVY substrate and $20 \mu \mathrm{l} \mathrm{sam-}$ ple lysate in a reaction mixture of $50 \mu \mathrm{l}$ in $0.2 \mathrm{M}$ Tris$\mathrm{HCl}, \mathrm{pH} \mathrm{7.4,} \mathrm{either} \mathrm{in} \mathrm{the} \mathrm{presence} \mathrm{or} \mathrm{absence} \mathrm{of}$ $0.03 \%$ sodium dodecyl sulfate (SDS). Experimental samples and appropriate controls were set up in triplicate and incubated for $1 \mathrm{~h}$ at $37^{\circ} \mathrm{C}$. The reaction was stopped by adding $190 \mu \mathrm{l}$ of $0.1 \mathrm{M}$ Tris- $\mathrm{HCl}, \mathrm{pH} 9.1$, and $60 \mu \mathrm{l}$ of $1 \%$ SDS to each well. The fluorescence was measured at $390 \mathrm{~nm}$ excitation and $440 \mathrm{~nm}$ emission.

\subsection{CYP2E1 activity}

CYP2E1 activity was determined by the hydroxylation of $p$-nitrophenol to 4-nitrocatechol catalyzed by CYP2E1 following an established method [27]. Reaction mixtures of $50 \mu 1$ containing $2 \mathrm{mM} \beta$-nicotinamide adenine dinucleotide phosphate and $0.8 \mathrm{mM} p$-nitrophenol (both from Sigma) were added to $1.5 \mathrm{ml}$ microcentrifuge tubes containing $50 \mu \mathrm{l}$ of microsomal suspension in triplicate on ice. Blank tubes of identical composition were prepared except that $20 \%$ TCA was added prior to the reaction mixture on ice. The reactions were terminated by adding $30 \mu \mathrm{l}$ of $20 \%$ TCA immediately after $1 \mathrm{~h}$ incubation at $37^{\circ} \mathrm{C}$ in a water bath shaker. After $15 \mathrm{~min}$, the sample and blank tubes were centrifuged for $10 \mathrm{~min}$ at $14,000 \mathrm{rpm}$ to remove insoluble proteins. Supernatants were transferred to 96-well plate and $10 \mu \mathrm{l}$ of $10 \mathrm{~N}$ $\mathrm{NaOH}$ were added for color development. The absorbance was read at $540 \mathrm{~nm}$ in the 96-well $V_{\max }$ kinetic reader (Molecular Devices). CYP2E1 activity from MDM microsome was calculated using 4-nitrocatechol (Sigma) as the internal standard. CYP2E1 activity was expressed as $\mathrm{nmol} / \mathrm{mg}$ protein.

\subsection{Western blot analyses}

Western blotting was performed as previously described [34]. Briefly, $10 \mu \mathrm{g}$ lysate protein was loaded onto $1.5 \mathrm{~mm}$ thick $4-15 \%$ gradient polyacrylamide precast gels (Bio-Rad, Hercules, CA) those were electrophoresed under denatured non-reducing conditions. Proteins from the gels were transblotted onto nitrocellulose membranes $(0.45 \mu \mathrm{m}$ pore size $)$ at $60 \mathrm{~V}$ for $1 \mathrm{~h}$ at $24^{\circ} \mathrm{C}$. The membranes were blocked with superblock (Bio-Rad) containing $2 \%$ nonfat dry milk for $40 \mathrm{~min}$ at $24^{\circ} \mathrm{C}$. Blots were incubated for $1 \mathrm{~h}$ at $24^{\circ} \mathrm{C}$ with the respective primary antibody in superblock solution that was 10 -fold diluted with $20 \mathrm{mM}$ phosphate buffer saline, $\mathrm{pH} 7.4$, containing $0.1 \%$ Tween 20 (PBST), followed by three successive washes with PBST for $5 \mathrm{~min}$. Immunoreactive bands were detected by luminol detection kit (Pierce, Rockford, IL) followed by exposure to Kodak X-ray film. The bands were quantified densitometrically as arbitrary volume integration units using the Molecular Dynamics ImageQuant software (Sunnyvale, CA). Results were expressed as the ratio of the density of the target protein immunoreactivity to that of the internal standard $\alpha$-actin immunoreactivity (which was not affected by EtOH treatment, HIV-1 infection or IFN- $\gamma$ ). The following Abs were used for Western blot: polyclonal Abs to $20 \mathrm{~S}$ and 19S, monoclonal Abs to LMP2 or LMP7 (all from Affinity Research Products, Mamhead, UK), polyclonal Abs to CYP2E1 (Research Diagnostic, Flander, NJ), and monoclonal Abs to 3-nitrotyrosine (Upstate Cell Signaling Solutions, Lake Placid, NY).

\subsection{ROS detection by the dichlorofluorescein diacetate assay}

Dichlorofluorescein diacetate (DCF-DA) (an indicator for ROS) is non-fluorescent until the acetate groups are removed by intracellular esterases and then oxidation occurs within the cell [35]. DCF-DA is converted to highly fluorescent DCF by cellular peroxides. The fluorescence is detected at excitation $488 \mathrm{~nm}$ and at emission $525 \mathrm{~nm}$ using a fluorescence plate reader. Sample mixtures contained $10 \mu 1$ of cell lysate, $50 \mu 1$ of DCF-DA (Molecular Probes, Eugene, OR) and $140 \mu \mathrm{l}$ of distilled water and incubated at $37^{\circ} \mathrm{C}$ for $15 \mathrm{~min}$ followed by the detection of fluorescence. The blank mixtures contained $50 \mu \mathrm{l}$ of methanol instead of $50 \mu \mathrm{l}$ of DCF-DA. The intensity values of the blanks were subtracted from the experimental sample intensity values. The results were expressed as specific mean fluorescence intensity per mg protein.

\subsection{Statistical analyses}

The significance of the effects of HIV-1, EtOH, and IFN- $\gamma$ on PR activity, CYP2E1 activity, ROS production, and expression of PR/IPR, CYP2E1 and 3-nitrotyrosine were assessed using two-way ANOVA with Newman-Keuls post-test for multiple comparisons. A $p$ value of $<0.05$ was considered significant.

\section{Results}

\subsection{HIV-1 infection decreases $P R$ activity and $P R / I P R$ content in $M D M$}

We first investigated the effect of MDM differentiation on the PR chymotrypsin-like activity. This increased 
13-fold from day one after monocyte isolation $(1.13 \pm 0.17 \mathrm{nmol} / \mathrm{mg}$ protein) through day nine $(14.82 \pm 0.19 \mathrm{nmol} / \mathrm{mg}$ protein), followed by a plateau phase (data not shown). HIV-1 infection of MDM resulted in $8-43 \%$ decline in the chymotrypsin-like activity 3-9 days after infection (Fig. 1A), while the normalized RT activity increased 6.5 times from days 3 to 9 post-infection $(1509,7593$, and $9800 \mathrm{cpm}$ RT activity, respectively, for days 3, 5, and 9 post-infection). A negative correlation was observed between level of RT activity and PR activity (correlation coefficient; $r=-0.804$, $p<0.01$ ) in HIV-1-infected MDM. The percentage of infected MDM at days 3, 5, and 9 were 3, 38, and $85 \%$, respectively, as determined by HIV-1 p 24 immunostain-
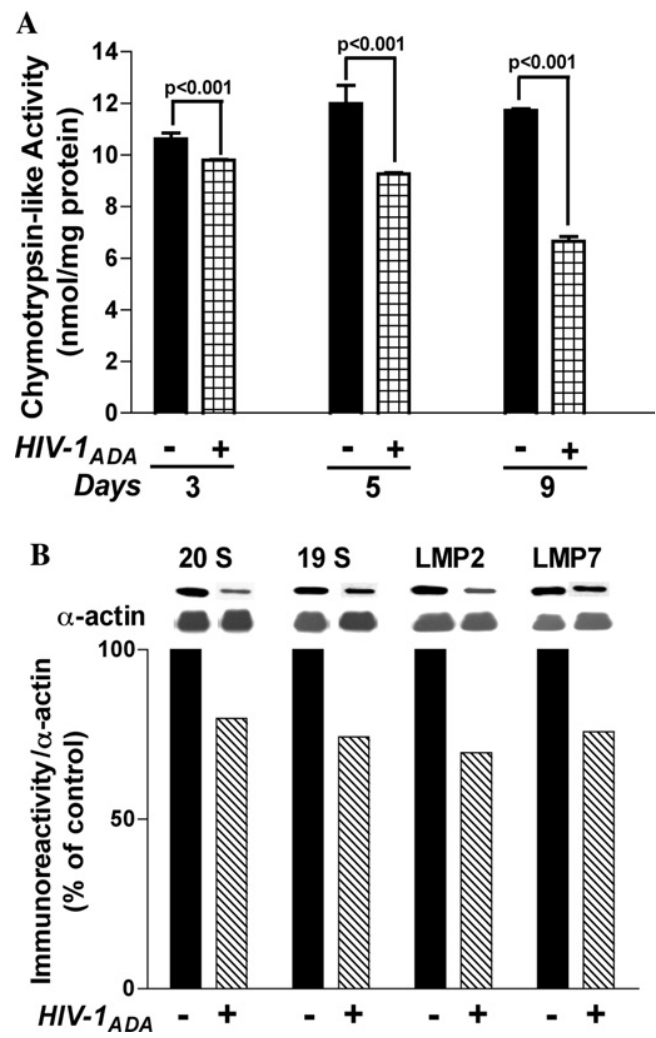

Fig. 1. Effects of HIV-1 infection on chymotrypsin-like activity and proteasome content in MDM. (A) Chymotrypsin-like activity was measured in HIV-1-infected MDM at days 3, 5, and 9 post-infection. We used 7-amino-4-methylcoumarin as an internal standard and $\mathrm{N}$ succinyl-LEU-LEU-VAL-TYR-7-amino-4-methylcoumarin (LLVY) as a fluorogenic peptide substrate for the PR activity assay. Fluorescence was measured at $390 \mathrm{~nm}$ (excitation) and $440 \mathrm{~nm}$ (emission). LLVY activity was expressed in $\mathrm{nmol} / \mathrm{mg}$ protein. (B) Content of $20 \mathrm{~S}$ constitutive PR, 19S regulatory (ATPase dependent) subunit of $26 \mathrm{~S}$ PR, LMP2, and LMP7 subunits of IPR were measured in uninfected or infected MDM at day 9 post-infection. Results were expressed as the ratio of target protein immunoreactivity to that of internal standard $\alpha$-actin. Values obtained from HIV-1 uninfected MDM were used as controls (normalized to a value of $100 \%$ ). Each bar was derived from mean value of four replicates \pm SEM. Data were statistically analyzed using two-way ANOVA with Newman-Keuls post-test. Representative data from four experiments performed with independent MDM donors are shown. ing. A modest decrease in cell viability of HIV-1 infected MDM (17-20\%) was detected at 3-9 days post-infection when compared to uninfected cells. The decline in PR activity was not due to cell death by HIV-1 infection, because each sample was extracted only from viable adherent MDM and all assays were performed in samples adjusted by protein content. Treatment of lysates from uninfected MDM with the 20S PR activator $0.03 \%$ SDS [36], resulted in 4-fold increase of activity indicating high levels of 20S PR. HIV-1-infected MDM demonstrated only 2-fold increase in PR activity in the presence of SDS, pointing to the impaired function of $20 \mathrm{~S}$ by HIV-1 infection in MDM (data not shown).

These functional changes paralleled expression of PR subunits detected by Western blot assays. HIV-1-infected MDM showed a 20\% (20S) and 26\% (19S) decrease when compared with uninfected cells $(p<0.001)$ (Fig. 1B). Expression of LMP2 and LMP7 subunits of IPR diminished by 30 and $24 \%(p<0.001)$, respectively (Fig. 1B), indicating that viral infection negatively affected IPR content in MDM. These results indicate a specific effect of HIV-1 infection on PR function/expression in MDM. These may not be attributed to HIV-induced changes in cell viability, because equal amount of protein was loaded from each sample for immunoblots and results were further normalized to internal standard ( $\alpha$-actin). Thus, decreased of PR/IPR activity and expression in HIV-1 infected MDM are related to the levels of HIV-1 infection and replication.

\subsection{Effects of IFN- $\gamma$ on $P R$ activity and PR/IPR content in $M D M$}

To mimic immune activation in HIV-1 infected cells, replicate infected or uninfected MDM were stimulated with IFN- $\gamma(10 \mathrm{ng} / \mathrm{ml})$. IFN- $\gamma$ up-regulated chymotrypsin-like activity in MDM $(199 \%, p<0.001)$ and HIV-1 $\operatorname{MDM}(218 \%, p<0.001)$ (Fig. 2A). Despite IFN- $\gamma$ treatment PR activity was $60 \%$ lower in infected as compared to uninfected IFN- $\gamma$ stimulated MDM. IFN- $\gamma$ treatment had no effect on cell viability (data not shown), IFN- $\gamma$ treatment did not alter the levels of $20 \mathrm{~S}$ or $19 \mathrm{~S}$ PR in both infected and uninfected MDM when compared to unstimulated cells (Fig. 2B). Contrary to the findings for constitutive PR, the levels of LMP2 and LMP7 (Fig. 2C) in IFN- $\gamma$-treated MDM were elevated by 29 and $27 \%$ when compared to non-treated cells $(p<0.001)$. Similarly, IFN- $\gamma$ treatment increased levels of LMP2 and LMP7 by 28 and 17\% in HIV-1-infected MDM $(p<0.001)$. In agreement with catalytic activity, expression of IPR was lower in virus-infected and IFN- $\gamma$-treated MDM (LMP2, 46\% and LMP7, 43\%, $p<0.001)$ when compared to IFN- $\gamma$-treated uninfected MDM. These results suggest that a major increase in PR activity seen after IFN- $\gamma$ stimulation is associated with IPR but not constitutive PR subunits. 

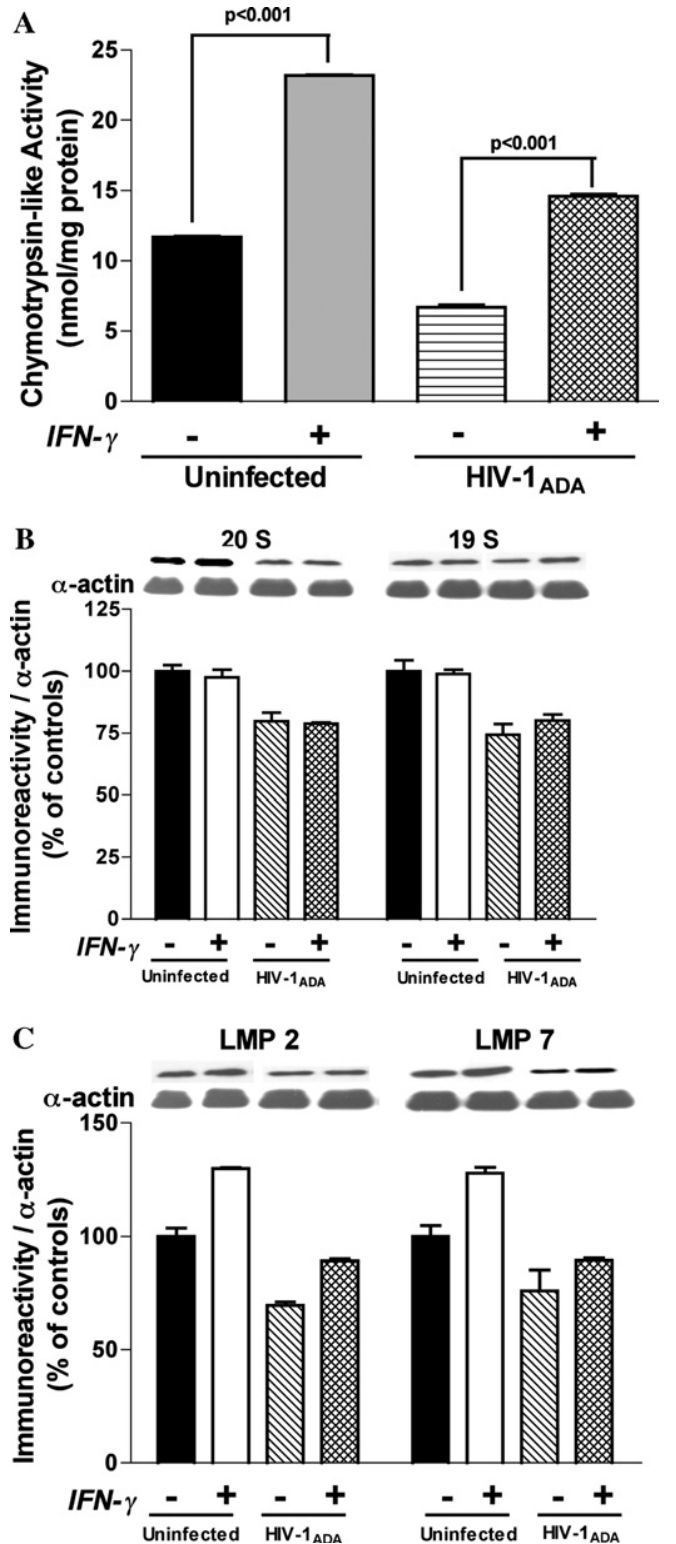

Fig. 2. Effects of IFN- $\gamma$ on proteasome activity and level of expression in MDM. (A) Changes in the proteasomal catalytic activity in MDM (day 9 post-infection) after $48 \mathrm{~h}$ stimulation with IFN- $\gamma$. (B) Content of 20S constitutive PR, 19S regulatory (ATPase dependent) subunit of 26S PR, and (C) LMP2 and LMP7 subunits of IPR were measured in uninfected or infected MDM at day 9 post-infection treated for $48 \mathrm{~h}$ with IFN $-\gamma$. Results were expressed as the ratio of target protein immunoreactivity to that of internal standard $\alpha$-actin. Values obtained from HIV-1 uninfected and IFN- $\gamma$ untreated MDM were used as a controls (normalized to a value of $100 \%$ ). Each bar was derived from mean value of four replicates \pm SEM. Data were statistically analyzed using two-way ANOVA with Newman-Keuls post-test. Representative data from four experiments performed with independent MDM donors are shown.

\subsection{Effects of EtOH on PR activity and PR/IPR content in $M D M$}

MDM were treated with $25 \mathrm{mM}$ EtOH. The concentration used was based on our initial experiments, which demonstrated that MDM viability or PR activity was not changed after $48 \mathrm{~h}$ treatment with $0.25-25 \mathrm{mM}$ $\mathrm{EtOH}$ (data not shown). Cell viability was adversely affected by EtOH concentrations higher than $25 \mathrm{mM}$ (data not shown). Although addition of $25 \mathrm{mM}$ EtOH did not change chymotrypsin-like activity in uninfected MDM (Fig. 3), it decreased PR activity (by 25\%, $p<0.001$ ) up-regulated by IFN- $\gamma$ to the levels seen in unstimulated cells (Fig. 3). Similar to the functional changes, EtOH decreased the levels of IFN- $\gamma$-induced IPR, LMP2, and LMP7 by $22 \%$ in EtOH/IFN- $\gamma$-treated MDM as compared to IFN- $\gamma$ stimulated MDM $(p<0.001$, Figs. $4 \mathrm{~A}$ and $\mathrm{B}$ ), while expression of $20 \mathrm{~S}$ and $19 \mathrm{~S}$ was not altered by EtOH treatment in uninfected cells (Figs. 4C and D). Exposure of infected MDM to EtOH prevented decrease of chymotrypsin-like activity by $7 \%(p<0.05$, day 3 , data not shown), $18 \%$ ( $p<0.02$, day 5 , data not shown), and $31 \%(p<0.001$, day 9 post-infection, Fig. 3 , bars 3 and 7). Opposite to results seen in uninfected cells, chymotrypsin-like activity in IFN- $\gamma$-stimulated HIV-1-infected MDM with EtOH treatment was moderately higher $(10 \%)$ as compared to IFN- $\gamma$ stimulated HIV-1-infected MDM without EtOH exposure ( $p<0.01$; Fig. 3 , bars 4 and 8 ). The contents of both constitutive PR and IPR were not changed after EtOH treatment of infected MDM as compared to untreated cells without IFN- $\gamma$ stimulation (Figs. 4A-D).

To establish whether EtOH had dose-dependent effects on PR activity, infected MDM were treated with varied concentrations of $\mathrm{EtOH}(0.25,2.5$, and $25 \mathrm{mM})$ for $8,24,48$, and $72 \mathrm{~h}$. All concentrations of EtOH had a protective effect on chymotrypsin-like activity in infected cells (Fig. 5). Treatment with EtOH (0.25$25 \mathrm{mM}$ ) for $48 \mathrm{~h}$ decreased RT activity by $26-33 \%$ $(p<0.01)$ (Fig. 5). These effects on PR activity were

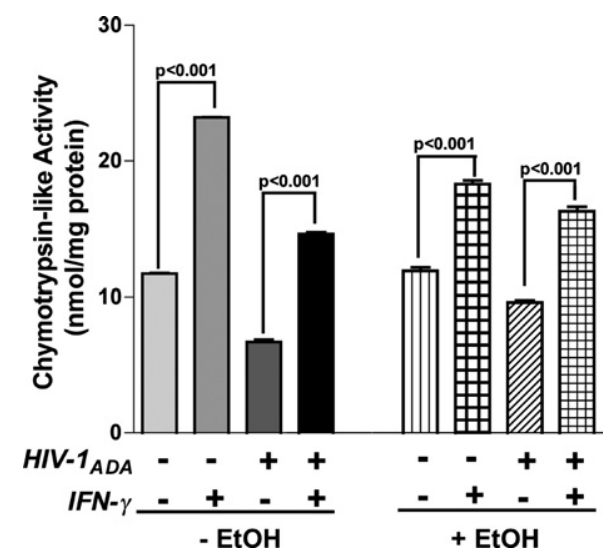

Fig. 3. Effects of EtOH on chymotrypsin-like activity in MDM. Changes in the proteasomal catalytic activity in MDM at day 9 postinfection after $48 \mathrm{~h}$ stimulation with IFN- $\gamma$ with or without simultaneous EtOH treatment. Values represent the mean of four determinations \pm SEM. Data were statistically analyzed using two-way ANOVA with Newman-Keuls post-test. Representative data from four experiments performed with independent MDM donors are shown. 

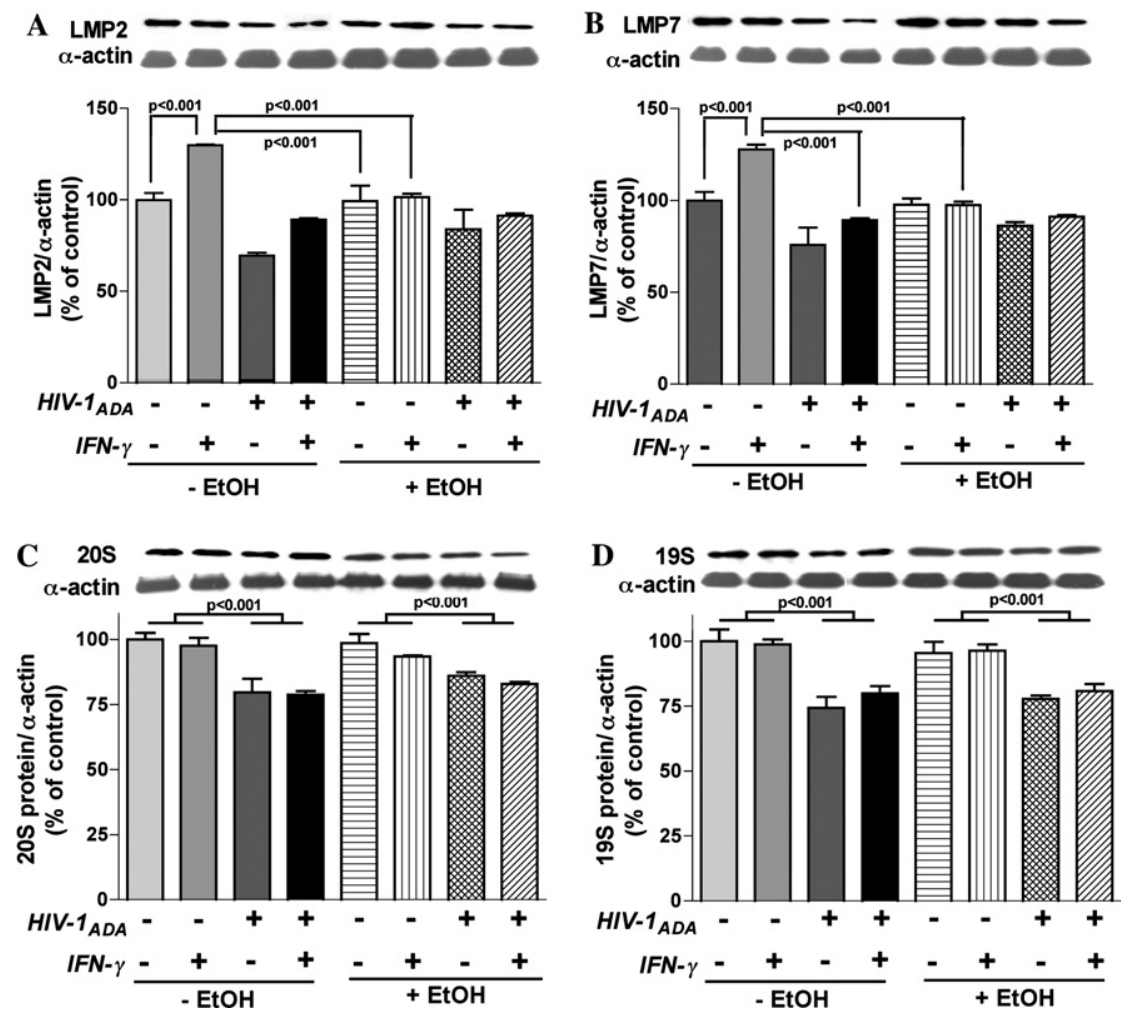

Fig. 4. Effects of EtOH on proteasome expression in MDM. Changes in the proteasome expression in MDM (day 9 post-infection) after $48 \mathrm{~h}$ stimulation with IFN- $\gamma$ with or without simultaneous EtOH treatment. Results were expressed as the ratio of target protein immunoreactivity to that of internal standard, actin. Values obtained from HIV-1 uninfected and IFN- $\gamma$ untreated MDM were used as a controls (normalized to a value of 100\%). (A) Ratio of LMP2/actin, (B) LMP7/actin, (C) 20S/actin, and (D) 19S/actin. Each bar was derived from mean value of four replicates \pm SEM. Data were statistically analyzed using two-way ANOVA with Newman-Keuls post-test. Representative data from four experiments performed with independent MDM donors are shown.

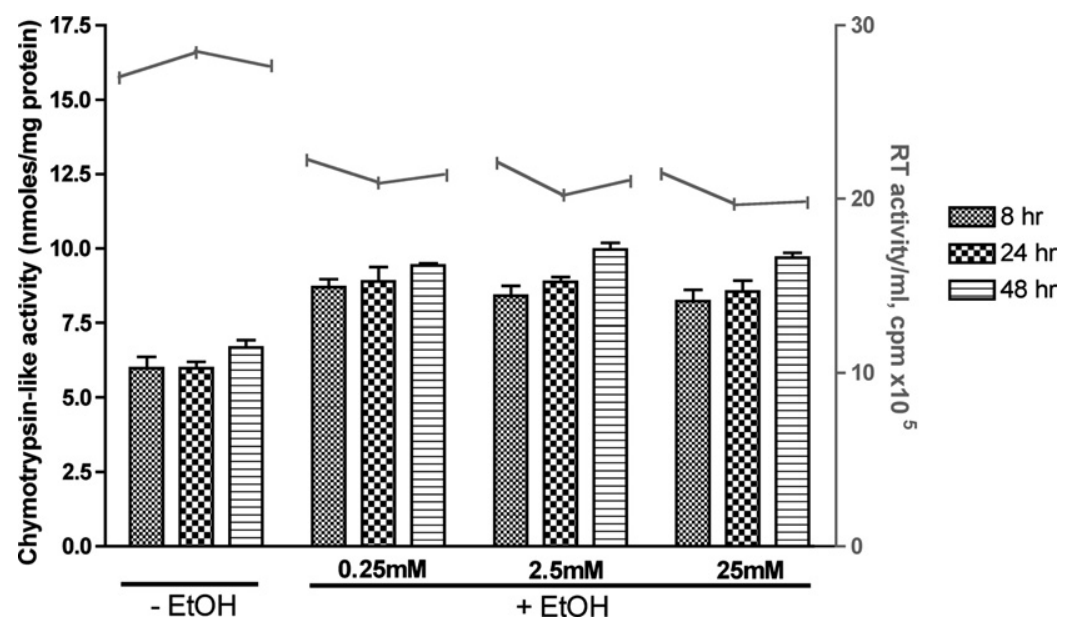

Fig. 5. Effects of EtOH concentrations on chymotrypsin-like activity and virus replication in HIV-1-infected MDM. Changes in PR and RT activities in HIV-1 infected MDM at day 9 post-infection after 8, 24 or $48 \mathrm{~h}$ treatment without or with different EtOH concentrations. Results obtained from HIV-1 infected MDM without EtOH treatment are indicated by "-EtOH" and with EtOH treatment indicated by "+EtOH." The bar graphs represent the PR activity (left $Y$ axis) and the line graphs above the bars show the RT activity (right $Y$ axis). Values are the mean of four determinations \pm SEM. Data were statistically analyzed using two-way ANOVA with Newman-Keuls post-test. Representative data from four experiments performed with independent MDM donors are shown.

inversely proportional to the levels of HIV-1 replication. Uninfected cells treated with $25 \mathrm{mM}$ EtOH and/or INF$\gamma$ served as positive controls (data not shown). As ex- pected, treatment of uninfected MDM with EtOH did not change PR activity, and INF- $\gamma$ treatment up-regulated PR activity. 
In summary, EtOH inhibited both INF- $\gamma$-induced IPR activity and increased IPR expression in uninfected MDM. EtOH decreased HIV-1 replication in infected MDM and ameliorated virus-induced decrease in PR activity. Inhibiting effects of EtOH on HIV-1 replication and IFN- $\gamma$-induced PR activity led to slight increase in PR activity in EtOH treated/IFN- $\gamma$ stimulated infected MDM.

\subsection{EtOH metabolism by CYP2E1 leads to ROS production in $M D M$}

CYP2E1 is suggested to be a major pathway for EtOH metabolism in MDM [37]. To further confirm this finding, we studied CYP2E1 enzyme activity in MDM. While modest CYP2E1 activity was found in uninfected MDM, it was increased by EtOH (1.8 fold, $p<0.001)$. However, levels of CYP2E1 activity were significantly lower in HIV-1-infected MDM (25-50\%), and were enhanced with EtOH treatment (2-fold) (Fig. 6A). HIV-1 infection resulted in $30 \%$ diminution of CYP2E1 content detected by Western blot assays in MDM (Fig. 6B). EtOH treatment up-regulated CYP2E1 content in both uninfected (3.3-fold) and infected MDM (2.6-fold) as compared to replicate untreated controls. These changes were comparable with alterations in functional activity
(Fig. 6A). Treatment with IFN- $\gamma$ did not change CYP2E1 expression in infected or uninfected cells (data not shown).

Since it is known that CYP2E1 activity is associated with oxygen radical production [38], we tested generation of ROS in MDM after EtOH exposure by DCF fluorescence assay. EtOH exposure significantly increased ROS (10-23\% increase in fluorescence intensity, $p<0.001)$ and this effect was less prominent in HIV-1-infected MDM (8-10\%), proportional to decreased activity of CYP2E1 $(p<0.001)$ (Fig. 6C). These data were substantiated by Western blot detection of $215 \mathrm{kDa}$ nitrated protein, an established marker of peroxynitrite oxidation [39]. As positive controls we used three nitrated proteins of molecular weight $16 \mathrm{kDa}$ (nitrated bovine superoxide dismutase), 66 kDa (nitrated bovine serum albumin) and $215 \mathrm{kDa}$ (nitrated rabbit muscle myosin). The level of $215 \mathrm{kDa}$ nitrated protein was significantly lower in HIV-1-infected MDM as compared to uninfected cells $(36 \%, p<0.001$, Fig. $6 \mathrm{D})$. EtOH treatment caused a $23 \%$ increase in nitrotyrosine content in uninfected MDM $(p<0.01)$ but it had no effect on its level in HIV-1-infected MDM (Fig. 6D). The expression levels of two nitrated proteins with lower molecular weight were very low in MDM.
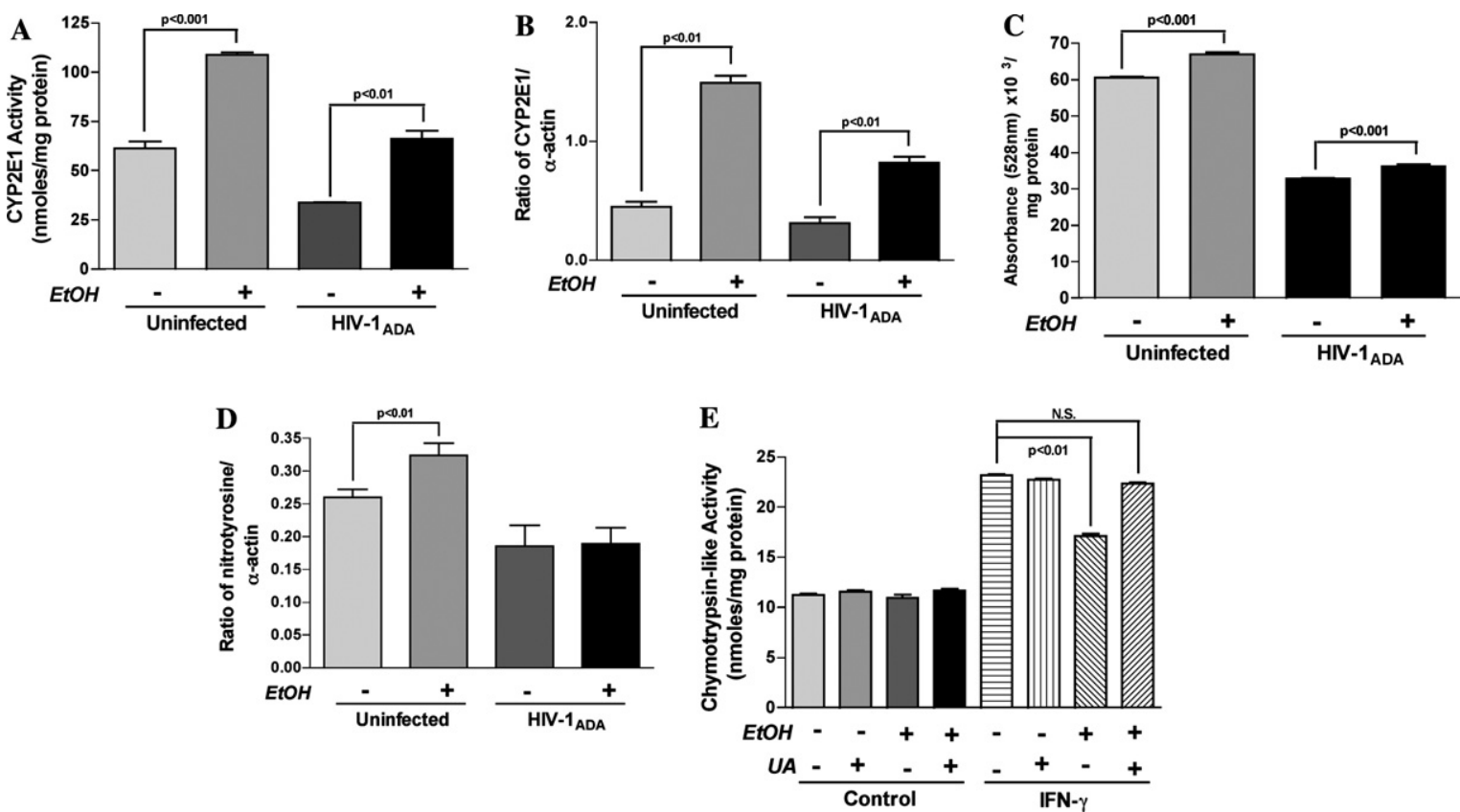

Fig. 6. Effects of HIV-1 infection, IFN- $\gamma$ and EtOH on CYP2E1 activity and content, ROS and their modulation by an antioxidant: (A) CYP2E1 activity (nmol/mg protein) in uninfected or HIV-1 infected MDM (9 day post-infection) after $48 \mathrm{~h}$ EtOH treatment (25 mM). (B) CYP2E1 content determined by Western blots using polyclonal anti-human CYP2E1. Data are expressed as ratio of denstitometric units for intensity of CYP2E1 to $\alpha$ actin. (C) DCF fluorescence was measured in identical MDM donors as specific mean fluorescence intensity per milligram protein. (D) Western blots analyses determined $215 \mathrm{kDa}$ nitrated protein immunoreactive species. Relative intensity was expressed as the ratio of nitrated protein to that of $\alpha$ actin band intensity. (E) Chymotrypsin-like activity (LLVY) was assayed in MDM treated with $25 \mathrm{mM} \mathrm{EtOH} \mathrm{or} \mathrm{IFN-} \gamma(10 \mathrm{ng} / \mathrm{ml})$ for $48 \mathrm{~h}$ followed by $1 \mathrm{~h}$ incubation with $100 \mu \mathrm{M}$ uric acid. Data were statistically analyzed using two-way ANOVA with Newman-Keuls post-test. Representative data from four experiments with four independent MDM donors are shown. 
Next, we determined whether ROS generated through CYP2E1 EtOH metabolism may lead to IPR dysfunction in MDM. In order to test this premise, we used a mild anti-oxidant, $100 \mu \mathrm{M}$ uric acid. Its application did not change PR activity in MDM, but it was able to restore chymotrypsin-like activity induced by IFN- $\gamma$ and down regulated by $\mathrm{EtOH}$ to control levels (Fig. $6 \mathrm{E})$. These results indicate that MDM exposure to EtOH increased CYP2E1 activity and expression, and EtOH metabolism by CYP2E1 led to ROS generation. ROS inhibited IPR activity in MDM. HIV-1 infected MDM demonstrated decreased activity/expression of CYP2E1 and less ROS production after EtOH treatment.

\section{Discussion}

This work sought to analyze the effects of EtOH and HIV-1 infection on PR function and on expression of PR/IPR in MDM. EtOH metabolism by CYP2E1 leads to ROS generation and may be responsible for IPR impairment in MDM. IPR seems to be susceptible to ROS generated via ethanol metabolism, because EtOH prevented IFN- $\gamma$-stimulated effects on PR activity and IPR content in MDM. Anti-oxidant reversed the effect of EtOH on IPR. HIV-1 infection decreased PR activity and PR/IPR content as well as CYP2E1 activity and expression. EtOH diminished viral replication attenuating inhibitory effect of HIV-1 on PR activity. CYP2E1 activity was decreased in HIV-1-infected cells resulting

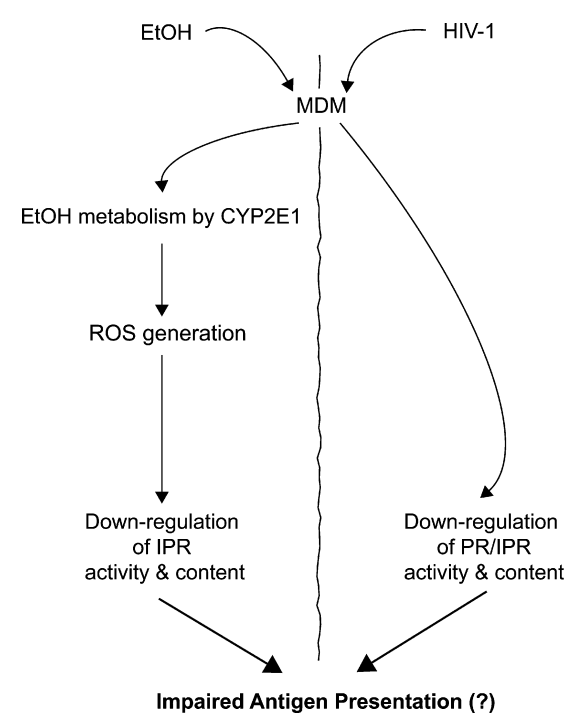

Fig. 7. Schematic representation of possible mechanistic pathway derived from the present findings. EtOH induces CYP2E1 activity in uninfected MDM, which in turn metabolizes $\mathrm{EtOH}$, leading to generation of ROS and subsequent decrease in IRP expression and function (shown on left flow chart). Infection of MDM with HIV-1 down regulates PR function and expression of PR/IPR (shown on right flow chart). Both EtOH and HIV-1 impair IPR in MDM and may result in inefficient antigen presentation. in less efficient EtOH metabolism by virus-infected cells and the absence of significant alterations in IPR activity already down regulated by viral infection (Fig. 7).

Similar to the findings reported for PR expression during maturation of dendritic cells [40], we found a significant increase in chymotrypsin-like activity during MDM differentiation (from days 3 to 9 in culture). In dendritic cells, this increase in PR activity was associated with a synthetic switch from constitutive PR to IPR [40]. Importantly, we found that differentiated MDM expressed high levels of IPR even without IFN$\gamma$ stimulation. Chymotrypsin-like activity decline in HIV-1 infected MDM was directly proportional to the level of virus replication. Decrease of PR activity in HIV-1-infected MDM was accompanied by diminished expression of PR and IPR as compared to uninfected MDM. This HIV-1 related decline in activity and expression may be associated with Tat-induced (transcriptional transactivator of HIV-1) PR malfunction $[41,42]$.

Immune response against viral or bacterial infection activates the PR regulator PA2 $\alpha / \beta$, thereby substituting constitutive subunits of PR with IPR subunits (LMP2, LMP7, and MELC-1) [21]. Indeed, IFN- $\gamma$ upregulated PR activity in MDM and HIV-1-infected MDM; however, PR activity was lower in infected cells even after IFN- $\gamma$ treatment as compared to MDM. While IFN- $\gamma$ had no effect on PR level, it increased LMP2/LMP7 expression in MDM indicating that major increase in PR activity after IFN- $\gamma$ stimulation is associated with IPR. Similar to catalytic activity, IPR expression was lower in HIV-1 infected and IFN- $\gamma$ stimulated MDM when compared to IFN- $\gamma$-treated uninfected MDM. Since HIV-1 alters catalytic activities of PR and expression of PR/IPR, these changes may interfere with processing of MHC class I antigens resulting in impaired antigen presentation. Thus, viral replication may negatively regulate elimination of infected cells by cytotoxic $\mathrm{T}$ lymphocytes.

Next, we examined the effects of EtOH on PR function and PR/IPR expression in MDM. EtOH treatment did not affect the activity or expression of PR in uninfected MDM, but it attenuated both IFN- $\gamma$-induced PR activity (predominantly associated with IPR) and enhanced LMP2/LMP7 expression in MDM. Currently, EtOH-induced inhibition of PR activity was demonstrated only in liver tissue derived from $\mathrm{EtOH}$-fed rats and mice $[29,43]$ and in hepatoma cell lines treated with EtOH (HepG2) [44]. In vivo studies suggest more prominent impairment of $26 \mathrm{~S}$ rather than $20 \mathrm{~S} \mathrm{PR}$ with $\mathrm{EtOH}$ treatment. While dysfunction of $26 \mathrm{~S}$ PR leads to inefficient degradation of short-lived abnormal proteins by the ubiquitin-PR pathway, EtOH-induced impairment of IPR in MDM found in this study may potentially result in impaired antigen presentation. In uninfected cells, EtOH not only diminished PR activity, but also 
decreased the levels of LMP2 and LMP7 content induced by IFN- $\gamma$ stimulation. It was shown that LMP2 and LMP7 deficient mice had reduced $\mathrm{CD} 8^{+} \mathrm{T}$ lymphocyte numbers and impaired antigen presentation $[45,46]$. EtOH-elicited IPR impairment observed for the first time in APC could underlie immunosuppressive effects of alcohol abuse [47].

Ethanol even at a low concentration protected the PR catalytic activity in HIV-1-infected MDM, possibly through suppression of virus replication. This protective effect of EtOH was not seen in the expression of 20S/19S or LMP2/LMP7 in infected MDM after EtOH treatment as compared as compared to HIV-1-infected MDM without EtOH exposure. However, it is not clear if this protection is an in vitro phenomenon, or if it exists in vivo in HIV patients with alcoholics.

Contrary to results seen in uninfected MDM, EtOH did not decrease PR activity up-regulated by IFN- $\gamma$ stimulation in HIV-1-infected MDM. This might be related to differences in EtOH metabolism in HIV-1-infected versus uninfected MDM. Thus, we examined activity and expression of CYP2E1 for EtOH metabolism in MDM. EtOH treatment resulted in increased CYP2E1 activity and expression in MDM, whereas HIV-1 infection reduced CYP2E1 activity and expression. Although CYP2E1 expression was demonstrated before in macrophages [26,48], this is the first report analyzing effects of EtOH and HIV-1 on CYP2E1 activity and expression in human MDM. The CYP2E1-mediated EtOH metabolism pathway leads to production of ROS [49] and superoxide anions in human macrophages [50]. Indeed, we detected higher levels of ROS in EtOH treated MDM, but found only a modest increase in HIV-1 MDM. These results closely paralleled activity and expression of CYP2E1. Detection of significantly higher levels of nitrotyrosine in uninfected EtOH treated MDM as compared to infected MDM under identical conditions further substantiated our observations. The absence of a significant increase of ROS after EtOH treatment in HIV-1 infected MDM may explain why IPR activity was not altered in infected cells after alcohol exposure. It was shown that IPR are more susceptible to ROS-mediated inhibition compared with constitutive PR [39]. Indeed, we were able to completely restore the IPR activity in EtOH-treated and IFN- $\gamma$ stimulated MDM by anti-oxidant.

In summary, the present study demonstrates that HIV-1 infection modulates function and expression of PR and IPR in APC. We found significant induction of CYP2E1 by EtOH treatment of uninfected MDM resulting in the enhanced production of ROS and decrease in IRP expression and function. IPR dysfunction could partially underlie immunosuppression observed in alcoholics or HIV-1-infected patients leading to defective antigenic peptide processing. Furthermore, our results indicate beneficial effects of anti-oxidants.

\section{Acknowledgments}

We thank Ms. Robin Taylor for excellent editorial support and Drs. Howard E. Gendelman and Jenae Limoges for critical reading of this work. This work was supported in part by NIH Grant RO1 AA013846-01 (to Y.P.).

\section{References}

[1] L. Penkower, M.A. Dew, L. Kingsley, J.T. Becker, P. Satz, F.W. Schaerf, K. Sheridan, Behavioral, health and psychosocial factors and risk for HIV infection among sexually active homosexual men: the Multicenter AIDS Cohort Study, Am. J. Public Health 81 (1991) 194-196.

[2] R.M. Crum, N. Galai, S. Cohn, D.D. Celentano, D. Vlahov, Alcohol use and T-lymphocyte subsets among injection drug users with HIV-1 infection: a prospective analysis, Alcohol Clin. Exp. Res. 20 (1996) 364-371.

[3] O. Bagasra, A. Howeedy, R. Dorio, A. Kajdacsy-Balla, Functional analysis of T-cell subsets in chronic experimental alcoholism, Immunology 61 (1987) 63-69.

[4] F. Mili, W.D. Flanders, J.R. Boring, J.L. Annest, F. DeStefano, The associations of alcohol drinking and drinking cessation to measures of the immune system in middle-aged men, Alcohol Clin. Exp. Res. 16 (1992) 688-694.

[5] T.R. Jerrells, C.A. Marietta, G. Bone, F.F. Weight, M.J. Eckardt, Ethanol-associated immunosuppression, Adv. Biochem. Psychopharmacol. 44 (1988) 173-185.

[6] R.M. Kaelin, A. Semerjian, D.M. Center, J. Bernardo, Influence of ethanol on human T-lymphocyte migration, J. Lab. Clin. Med. 104 (1984) 752-760.

[7] G. Szabo, B. Verma, D. Catalano, Selective inhibition of antigenspecific $\mathrm{T}$ lymphocyte proliferation by acute ethanol exposure: the role of impaired monocyte antigen presentation capacity and mediator production, J. Leukoc. Biol. 54 (1993) 534-544.

[8] O. Bagasra, A. Howeedy, A. Kajdacsy-Balla, Macrophage function in chronic experimental alcoholism. I. Modulation of surface receptors and phagocytosis, Immunology 65 (1988) 405409.

[9] L.E. Bermudez, L.S. Young, Ethanol augments intracellular survival of Mycobacterium avium complex and impairs macrophage responses to cytokines, J. Infect Dis. 163 (1991) 1286-1292.

[10] M. Bukara, A.P. Bautista, Acute alcohol intoxication and gadolinium chloride attenuate endotoxin- induced release of CC chemokines in the rat, Alcohol 20 (2000) 193-203.

[11] S. Arbabi, I. Garcia, G.J. Bauer, R.V. Maier, Alcohol (ethanol) inhibits IL-8 and TNF: role of the p38 pathway, J. Immunol. 162 (1999) 7441-7445.

[12] S. Nelson, G.J. Bagby, B.G. Bainton, W.R. Summer, The effects of acute and chronic alcoholism on tumor necrosis factor and the inflammatory response, J. Infect Dis. 160 (1989) 422-429.

[13] M. Kawakami, B.R. Switzer, S.R. Herzog, A.A. Meyer, Immune suppression after acute ethanol ingestion and thermal injury, J. Surg. Res. 51 (1991) 210-215.

[14] L.M. Gentilello, R.A. Cobean, A.P. Walker, E.E. Moore, M.J. Wertz, E.P. Dellinger, Acute ethanol intoxication increases the risk of infection following penetrating abdominal trauma, J. Trauma 34 (1993) 669-674 (Discussion 674-675).

[15] H. Chen, Y.K. Yip, I. George, M. Tyorkin, E. Salik, K. Sperber, Chronically HIV-1-infected monocytic cells induce apoptosis in cocultured T cells, J. Immunol. 161 (1998) 4257-4267.

[16] D.A. Stoltz, S. Nelson, J.K. Kolls, P. Zhang, R.P. Bohm Jr., M. Murphey-Corb, G.J. Bagby, In vitro ethanol suppresses alveolar 
macrophage TNF-alpha during simian immunodeficiency virus infection, Am. J. Respir. Crit. Care Med. 161 (2000) 135-140.

[17] G.N. DeMartino, C.A. Slaughter, The proteasome, a novel protease regulated by multiple mechanisms, J. Biol. Chem. 274 (1999) 22123-22126.

[18] M. Bochtler, L. Ditzel, M. Groll, C. Hartmann, R. Huber, The proteasome, Annu. Rev. Biophys. Biomol. Struct. 28 (1999) 295317.

[19] P.M. Kloetzel, A. Soza, R. Stohwasser, The role of the proteasome system and the proteasome activator PA28 complex in the cellular immune response, Biol. Chem. 380 (1999) 293-297.

[20] K. Fruh, A. Gruhler, R.M. Krishna, G.J. Schoenhals, A comparison of viral immune escape strategies targeting the MHC class I assembly pathway, Immunol. Rev. 168 (1999) 157-166.

[21] S. Khan, M. van den Broek, K. Schwarz, R. de Giuli, P.A. Diener, M. Groettrup, Immunoproteasomes largely replace constitutive proteasomes during an antiviral and antibacterial immune response in the liver, J. Immunol. 167 (2001) 6859-6868.

[22] D. Nandi, K. Marusina, J.J. Monaco, How do endogenous proteins become peptides and reach the endoplasmic reticulum, Curr. Top. Microbiol. Immunol. 232 (1998) 15-47.

[23] M. Groettrup, A. Soza, U. Kuckelkorn, P.M. Kloetzel, Peptide antigen production by the proteasome: complexity provides efficiency, Immunol. Today 17 (1996) 429-435.

[24] T.M. Donohue Jr., R.K. Zetterman, Z.Q. Zhang-Gouillon, S.W. French, Peptidase activities of the multicatalytic protease in rat liver after voluntary and intragastric ethanol administration, Hepatology 28 (1998) 486-491.

[25] C.S. Lieber, Ethanol metabolism, cirrhosis and alcoholism, Clin. Chim. Acta 257 (1997) 59-84.

[26] J.L. Hutson, S.N. Wickramasinghe, Expression of CYP2E1 by human monocyte-derived macrophages, J. Pathol. 188 (1999) 197200.

[27] D.R. Koop, A. Chernosky, E.P. Brass, Identification and induction of cytochrome P450 2E1 in rat Kupffer cells, J. Pharmacol. Exp. Ther. 258 (1991) 1072-1076.

[28] S.N. Wickramasinghe, Observations on the biochemical basis of ethanol metabolism by human macrophages, Alcohol Alcohol 21 (1986) 57-63.

[29] F. Bardag-Gorce, Q.X. Yuan, J. Li, B.A. French, C. Fang, M. Ingelman-Sundberg, S.W. French, The effect of ethanol-induced cytochrome p4502E1 on the inhibition of proteasome activity by alcohol, Biochem. Biophys. Res. Commun. 279 (2000) 23-29.

[30] Z. Gouillon, D. Lucas, J. Li, A.L. Hagbjork, B.A. French, P. Fu, C. Fang, M. Ingelman-Sundberg, T.M. Donohue Jr., S.W. French, Inhibition of ethanol-induced liver disease in the intragastric feeding rat model by chlormethiazole, Proc. Soc. Exp. Biol. Med. 224 (2000) 302-308.

[31] H.E. Gendelman, J.M. Orenstein, M.A. Martin, C. Ferrua, R. Mitra, T. Phipps, L.A. Wahl, H.C. Lane, A.S. Fauci, D.S. Burke, et al., Efficient isolation and propagation of human immunodeficiency virus on recombinant colony-stimulating factor 1-treated monocytes, J. Exp. Med. 167 (1988) 1428-1441.

[32] A. Ghorpade, A. Nukuna, M. Che, S. Haggerty, Y. Persidsky, E. Carter, L. Carhart, L. Shafer, H.E. Gendelman, Human immunodeficiency virus neurotropism: an analysis of viral replication and cytopathicity for divergent strains in monocytes and microglia, J. Virol. 72 (1998) 3340-3350.

[33] M. Manthorpe, R. Fagnani, S.D. Skaper, S. Varon, An automated colorimetric microassay for neuronotrophic factors, Brain Res. 390 (1986) 191-198.

[34] J. Haorah, D.L. McVicker, J.C. Byrd, R.G. MacDonald, T.M. Donohue Jr., Chronic ethanol administration decreases the ligand binding properties and the cellular content of the mannose 6phosphate/insulin-like growth factor II receptor in rat hepatocytes, Biochem. Pharmacol. 63 (2002) 1229-1239.

[35] S.S. Barbieri, S. Eligini, M. Brambilla, E. Tremoli, S. Colli, Reactive oxygen species mediate cyclooxygenase-2 induction during monocyte to macrophage differentiation: critical role of NADPH oxidase, Cardiovasc. Res. 60 (2003) 187-197.

[36] T. Shibatani, W.F. Ward, Sodium dodecyl sulfate (SDS) activation of the $20 \mathrm{~S}$ proteasome in rat liver, Arch. Biochem. Biophys. 321 (1995) 160-166.

[37] S.N. Wickramasinghe, Supernatants from ethanol-containing macrophage cultures have cytotoxic activity, Alcohol Alcohol 21 (1986) 263-268.

[38] F. Bardag-Gorce, J. Li, B.A. French, S.W. French, Ethanol withdrawal induced CYP2E1 degradation in vivo, blocked by proteasomal inhibitor PS-341, Free Radic. Biol. Med. 32 (2002) $17-21$.

[39] M. Amici, G. Lupidi, M. Angeletti, E. Fioretti, A.M. Eleuteri, Peroxynitrite-induced oxidation and its effects on isolated proteasomal systems, Free Radic. Biol. Med. 34 (2003) 987-996.

[40] A. Macagno, M. Gilliet, F. Sallusto, A. Lanzavecchia, F.O. Nestle, M. Groettrup, Dendritic cells up-regulate immunoproteasomes and the proteasome regulator PA28 during maturation, Eur. J. Immunol. 29 (1999) 4037-4042.

[41] X. Huang, U. Seifert, U. Salzmann, P. Henklein, R. Preissner, W. Henke, A.J. Sijts, P.M. Kloetzel, W. Dubiel, The RTP site shared by the HIV-1 Tat protein and the 11S regulator subunit alpha is crucial for their effects on proteasome function including antigen processing, J. Mol. Biol. 323 (2002) 771-782.

[42] G.S. Apcher, S. Heink, D. Zantopf, P.M. Kloetzel, H.P. Schmid, R.J. Mayer, E. Kruger, Human immunodeficiency virus-1 Tat protein interacts with distinct proteasomal alpha and beta subunits, FEBS Lett. 553 (2003) 200-204.

[43] V. Fataccioli, E. Andraud, M. Gentil, S.W. French, H. Rouach, Effects of chronic ethanol administration on rat liver proteasome activities: relationship with oxidative stress, Hepatology 29 (1999) 14-20.

[44] N.A. Osna, D.L. Clemens, T.M. Donohue Jr., Interferon gamma enhances proteasome activity in recombinant Hep G2 cells that express cytochrome P4502E1: modulation by ethanol, Hepatology 66 (2003) 697-710.

[45] H.J. Fehling, W. Swat, C. Laplace, R. Kuhn, K. Rajewsky, U. Muller, H. von Boehmer, MHC class I expression in mice lacking the proteasome subunit LMP-7, Science 265 (1994) 1234-1237.

[46] L. Van Kaer, P.G. Ashton-Rickardt, M. Eichelberger, M. Gaczynska, K. Nagashima, K.L. Rock, A.L. Goldberg, P.C. Doherty, S. Tonegawa, Altered peptidase and viral-specific T cell response in LMP2 mutant mice, Immunity 1 (1994) 533-541.

[47] G. Szabo, P. Mandrekar, A. Dolganiuc, D. Catalano, K. Kodys, Reduced alloreactive T-cell activation after alcohol intake is due to impaired monocyte accessory cell function and correlates with elevated IL-10, IL-13, and decreased IFNgamma levels, Alcohol Clin. Exp. Res. 25 (2001) 1766-1772.

[48] J.M. Baron, G. Zwadlo-Klarwasser, F. Jugert, W. Hamann, A. Rubben, H. Mukhtar, H.F. Merk, Cytochrome P450 1B1: a major P450 isoenzyme in human blood monocytes and macrophage subsets, Biochem. Pharmacol. 56 (1998) 1105-1110.

[49] Y. Xu, M.A. Leo, C.S. Lieber, Lycopene attenuates alcoholic apoptosis in HepG2 cells expressing CYP2E1, Biochem. Biophys. Res. Commun. 308 (2003) 614-618.

[50] S.N. Wickramasinghe, Role of superoxide anion radicals in ethanol metabolism by blood monocyte-derived human macrophages, J. Exp. Med. 169 (1989) 755-763. 